\title{
MÔ HİNH THẤM NƯỞC MƯA PHỤC VỤ PHÂN TÍCH ỔN ĐỊNH SƯỜN DỐC KHU VỰC THI TRẤN CỐC PÀI - HUYỆN XÍN MẦN - TİNH HÀ GIANG
}

\author{
NGUYẼ̃N VĂN HOÀNG ${ }^{1}$, ÚNG QUỐC KHANG ${ }^{2}$ \\ E-mail: n_v_hoang_vdc@yahoo.com \\ ${ }^{I}$ Viện Địa chất - Viện KH\&CN Việt Nam, \\ ${ }^{2}$ Tổng cuc Thủy lợi-Bộ NN\&PTNT
}

Ngày nhận bài: 17-9-2010

\section{Mở đầu}

Hàng năm vào mùa mưa bão hiện tượng trượt lở sườn dốc xảy ra mạnh mẽ ở các tỉnh miền núi, đặc biệt là các tỉnh Cao Bằng, Lào Cai, Hà Giang,... Đặc biệt vào mùa mưa năm 2007- 2008, hiện tượng trượt lở xảy ra mạnh mẽ ở thị trấn Cốc Pài-huyện Xín Mần - tỉnh Hà Giang, phát triển mạnh mẽ khu vực trung thị trấn, khu nhà UBND huyện và nhà làm việc của các phòng ban nằm trên một khối trượt lớn có chiều dài $350-500 \mathrm{~m}$, chiều rộng $150-200 \mathrm{~m}$. Nhiều nhà dân, đường giao thông và đài tưởng niệm nằm trên khối trượt này đều bị nứt và biến dạng nghiêm trọng. Trước nguy cơ trượt nghiêm trọng ở trung tâm Huyện Lỵ Xín Mần, Chính phủ đã có ý kiến chỉ đạo về việc xử lý trượt lở đất khu vực trung tâm huyện lỵ Xín Mần (thị trấn Cốc Pài), tỉnh Hà Giang. Để đưa ra được các giải pháp hợp lý xử lý trượt lở đất khu vực đòi hỏi phải có cơ sở khoa học đánh giá đúng mức độ nguy hiểm về trượt lở, các nguyên nhân chính trực tiếp gây trượt lở nhằm đưa ra các giải pháp phù hợp với thực tế, đạt hiệu quả kinh tế - xã hội và phòng tránh. Tính toán và dự báo được lượng nước mưa ngấm vào đất theo thời gian và theo độ sâu là cơ sở quan trọng trong tính toán đánh giá độ ổn định sườn dốc, dự báo nguy cơ trượt lở dưới tác động của mưa, đồng thời đưa ra giải pháp kỹ thuật tiêu thoát nước ngầm phù hợp nhằm đảm bảo độ ổn định sườn dốc. Ngoài ra, kết quả mô phỏng quá trình ngấm nước mưa vào đất trợ giúp đắc lực cho tính toán chính xác dòng chảy mặt, là thông số quan trọng trong thiết kế hệ thống thu gom nước mặt đối với các sườn dốc.

\section{Vai trò của mưa đối với trượt lở}

Yếu tố mưa tạo ra các điều kiện thuận lợi cho trượt có thể được định lượng hóa là: 1) đất có độ ẩm tăng lên do mưa ngấm sẽ làm tăng khối lượng, giảm lực kháng cắt và góc ma sát trong; 2) làm tăng áp lực nước lỗ rổng trong đất, ở những điều kiện địa chất thủy văn nhất định sẽ làm tăng mực nước ngầm, tức là tăng lực đẩy nổi của đất. Thí dụ về giảm lực kháng cắt và góc ma sát trong của đất do tăng độ ẩm có thể được minh họa qua thí dụ trên hình 1 [1] cho thấy rằng sự biến đổi đột ngột của các thông số kháng cắt xảy ra khi đất chuyển từ trạng thái cứng sang dẻo.

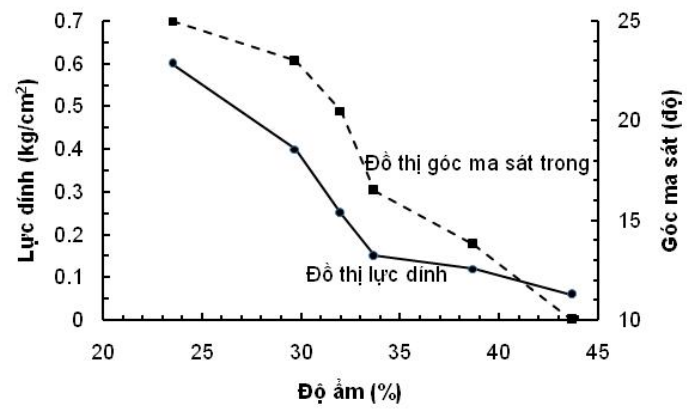

Hình 1. Biến thiên lực dính và góc ma sát trong theo độ ẩm

Mặt cắt qua qua các lỗ khoan khu vực trung tâm thị trấn Cốc Pài (hình 2), nơi có khối trượt lớn nhất về kích thước và mức độ dịch trượt, có mặt 5 lớp như sau [6]: 
- Lớp (1): đất lấp, sườn tích, đất sét pha, dăm sạn.

- Lớp (2): sét pha màu xám ghi, xám vàng.

- Lớp (3): sét pha lẫn dăm sạn màu xám ghi, xám vàng.

- Lớp (4): phiến sericit phong hóa màu xám ghi, xám đen.

- Lớp (5): đá phiến sericit màu xám ghi, xám sáng.

Như vậy, phần trên của mặt cắt tới độ sâu $15 \mathrm{~m}$ $20 \mathrm{~m}$ là các lớp 1 đến 3 là đất sét, sét pha lẫn dăm sạn. Các kết quả thí nghiệm các chỉ tiêu cơ lý các mẫu đất khu vực cho thấy ở trạng thái bão hòa nước đất các lớp 1-3 có các chỉ tiêu cơ học thấp hơn đáng kể so với trạng thái tự nhiên có độ ẩm thấp [6]: lực dính kết giảm $28 \%$ và góc ma sát trong giảm $14 \%$. Việc mô hình chính xác quá trình ngấm nước mưa cho phép xác định chính xác độ âm của đất theo không gian và thời gian và do đó sẽ xác định được các chỉ tiêu cơ lý của đất ứng với các độ ẩm này phục vụ cho tính toán chính xác nguy cơ trượt đât, tức là cảnh báo trước nguy cơ trượt lở trong tiến trình mưa nhất định.

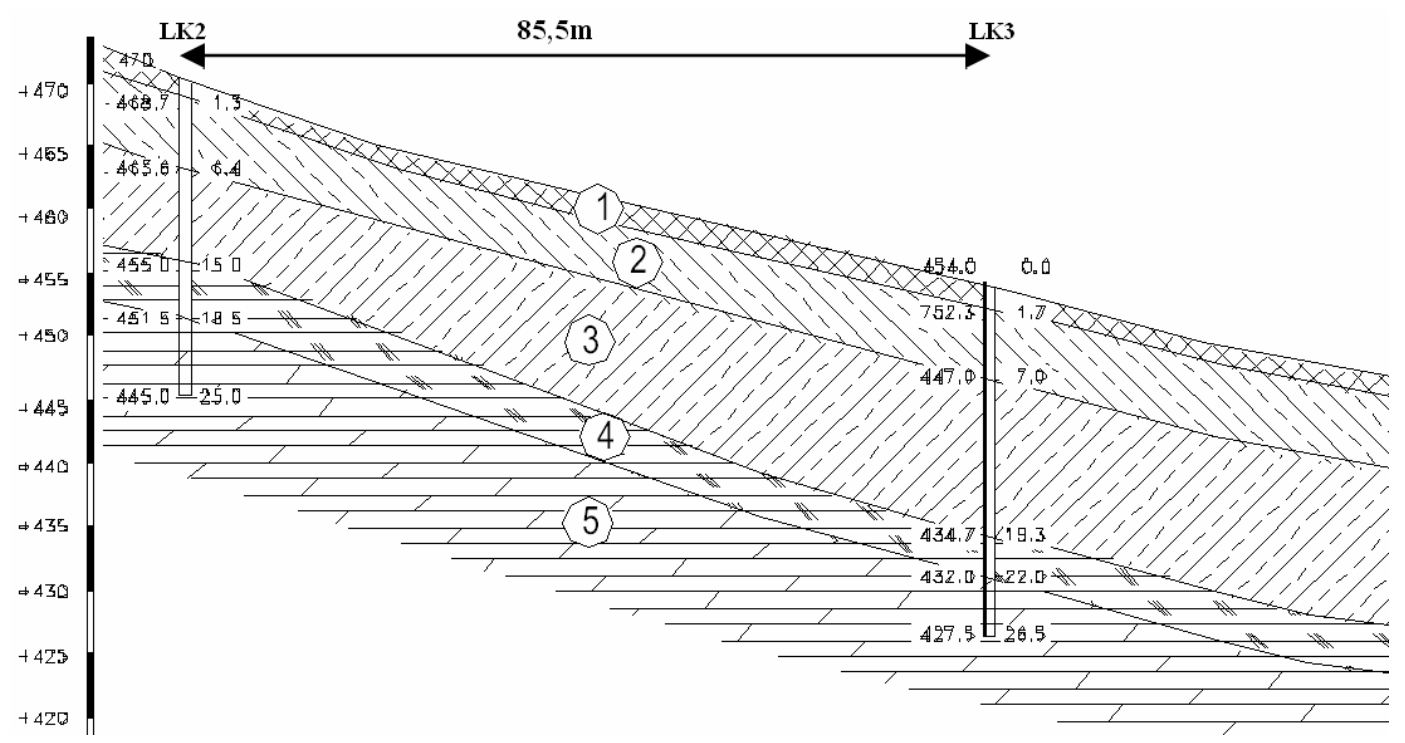

Hình 2. Mặt cắt khu vực trung tâm thị trấn Cốc Pài (qua UBND huyện)[6]

\section{Cơ chế quá trình ngấm nước mưa}

\subsection{Phương trình lan truyền ẩm trong đất}

Khi nước mưa rơi xuống mặt đất, một phần bị bốc hơi, một phần ngấm xuống đất và một phần chảy tràn trên mặt đất. Trong nghiên cứu trượt lở dưới ảnh hưởng của mưa, có thể tính toán lượng nước mưa thấm vào đất bằng mô hình số. Phương trình mô tả quá trình lan truyền nước trong đất không bão hòa nước theo phương thẳng đứng từ trên xuống có dạng sau [2]:

$$
\frac{\partial \theta_{w}}{\partial t}=\frac{\partial}{\partial z}\left\{D\left(\theta_{w}\right) \frac{\partial p}{\partial z}\right\}-\frac{\partial K\left(\theta_{w}\right)}{\partial z}
$$

trong đó: $\theta_{w}$ là độ ẩm tương đối của đất (lượng nước chứa trong một đơn vị thể tích đất), $t$ là thời gian, $p$ là áp suất nước (hoặc là áp lực hút tuyệt đối); $\gamma$ là dung trọng của nước và $D\left(\theta_{w}\right)$ là hệ số phân tán ẩm trong đất có đơn vị là $\mathrm{L}^{2} \mathrm{~T}^{-1}$.

Như vậy để mô hình được quá trình lan truyền ẩm đối với một môi trường đất nhất định nào đó phải biết được quan hệ giữa hệ số thấm không bão hòa và độ ẩm cũng như giữa áp lực hút nước tuyệt đối và độ ẩm. Trong khuôn khổ của nghiên cứu này, các tác giả sử dụng quan hệ áp lực hút tuyệt đối ( $p$ tính bằng $\mathrm{m}$ ) và độ ẩm và giữa hệ số thấm không bão hòa (tính bằng $\mathrm{m} / \mathrm{s}$ ) và độ ẩm $\left(\theta_{w}\right)$ theo Jiunsheng Li and Hiroshi Kawano (1997) [3]:

$$
\begin{array}{ll}
p=1,66\left(\frac{\theta_{w}}{\theta_{B H}}\right)^{-5,70} & \theta_{w} \leq 0,35 \\
p=0,09\left(\frac{\theta_{w}}{\theta_{B H}}\right)^{-27,21} & \theta_{w^{\prime}}>0,35
\end{array}
$$




$$
\begin{array}{ll}
K\left(\theta_{w}\right)=8,33 \times 10^{-7}\left(\frac{\theta_{w}}{\theta_{B H}}\right)^{16,37} & \theta_{w} \leq 0,35 \\
K\left(\theta_{w}\right)=1,33 \times 10^{-5}\left(\frac{\theta_{w}}{\theta_{B H}}\right)^{42,08} & \theta_{w}>0,35
\end{array}
$$

Từ (2) và (3) ta có hệ số phân tán ẩm $\left(D\left(\theta_{w}\right)\right.$ tính bằng $\mathrm{m}^{2} / \mathrm{s}$ ) là:

$$
\begin{aligned}
& \mathrm{D}\left(\theta_{\mathrm{w}}\right)=8,33 \times 10^{-7}\left(\frac{\theta_{\mathrm{W}}}{\theta_{\mathrm{BH}}}\right)^{16,37} \times \\
& \times 9,462\left(\frac{\theta_{\mathrm{W}}}{\theta_{\mathrm{BH}}}\right)^{-6,70} \theta_{\mathrm{W}} £ 0,35 \\
& \mathrm{D}\left(\theta_{\mathrm{W}}\right)=1,33 \times 10^{-5}\left(\frac{\theta_{\mathrm{W}}}{\theta_{\mathrm{BH}}}\right)^{42,08} \times \\
& \times 2,4489\left(\frac{\theta_{\mathrm{W}}}{\theta_{\mathrm{BH}}}\right)^{-28,21} \theta_{\mathrm{W}}>0,35
\end{aligned}
$$

Trong đó: $\theta_{B H}$ là độ ẩm bão hoà, $K\left(\theta_{w}\right)$ là hệ số thấm không bão hòa (là hàm số nhất định của độ ẩm đối với mỗi loại đất).

Phương trình (1) chỉ có lời giải duy nhất khi có đầy đủ các điều kiện ban đầu và điều kiện biên được mô tả như sau.

Điều kiện ban đầu là phân bố độ ẩm vào thời điểm ban đầu $t=t_{0}$ tại mọi vị trí trong miền tính toán:

$$
\theta_{w}=\theta_{w}^{0}(z)
$$

Các điều kiện biên có thể là một hoặc đồng thời các dạng sau:

- Biên có độ ẩm và áp suất đã biết:

$$
\theta_{w}=\theta_{w}^{w} \text { trên } \Gamma_{w}
$$

- Biên Neumann (gradient độ ẩm pháp tuyến với đường biên đã biết):

$$
\frac{\partial \theta_{w}}{\partial \mathrm{n}}=g \operatorname{trên} \Gamma_{g_{w}}
$$

\subsection{Phương pháp phần tử hũu hạn}

Phương pháp mô hình số (chẳng hạn phần tử hữu hạn) có thể được sử dụng để giải phương trình (1) tính toán ngấm nước mưa trong đất. Hệ phương trình tuyến tính cho từng bước thời gian được thiết lập theo đúng trình từ mô tả trong các phương trình
$(1 \div 4)$. Trong từng bước thời gian các thông số về giá trị lượng nước được cung cấp từ mặt đất, hệ số thấm không bão hoà $(K(w))$, hệ số phân tán ẩm $\left(D\left(\theta_{w}\right)\right.$, độ ẩm ở biên phía dưới $\left(\theta_{L}\right)$ được thay đổi theo đúng giá trị thực tế (lượng nước mưa rơi trên bề mặt) hoặc theo các quan hệ giữa các thông số đó với độ ẩm (các công thức 2-4).

Theo phương pháp phần tử hữu hạn, chia miền mô hình lan truyền ẩm ra $M$ phần tử và số bước thời gian chạy mô hình là $N$. Áp dụng phương pháp phần tử hữu hạn cho phương trình 1 với sơ đồ sai phân trung tâm về thời gian với các điều kiện biên nhất định ta có hệ phương trình tuyến tính (Huyakorn Pinder, 1987)[4]:

$$
\left(-2+\Delta t_{n} \mathrm{~K}\right) \theta_{w}^{n+1{ }^{n+1}}=-\left(2+\Delta t_{n} \mathrm{~K}\right) \theta_{w}^{n}+\mathrm{F}
$$

Trong đó $\mathrm{K}$ gọi là là ma trận cứng hình vuông kích thước $M \times M$ phụ thuộc vào kích thước phần tử và hệ số phân tán ẩm, $\theta_{\mathrm{w}}^{n}$ và $\theta_{\mathrm{w}}^{n+1}$ tương ứng là ma trận cột có $M$ hàng là độ ẩm tại các ô lưới vào bước thời gian thứ $n$ và $n+1, \mathrm{~F}$ là ma trận cột có $M$ hàng phụ thuộc vào kích thước phần tử và điều kiện biên cụ thể $\Delta t_{n}$ là bước thời gian tại bước mô hình thứ $n$.

Sơ đồ mô hình lan truyền ẩm được thể hiện trên hinh 3.

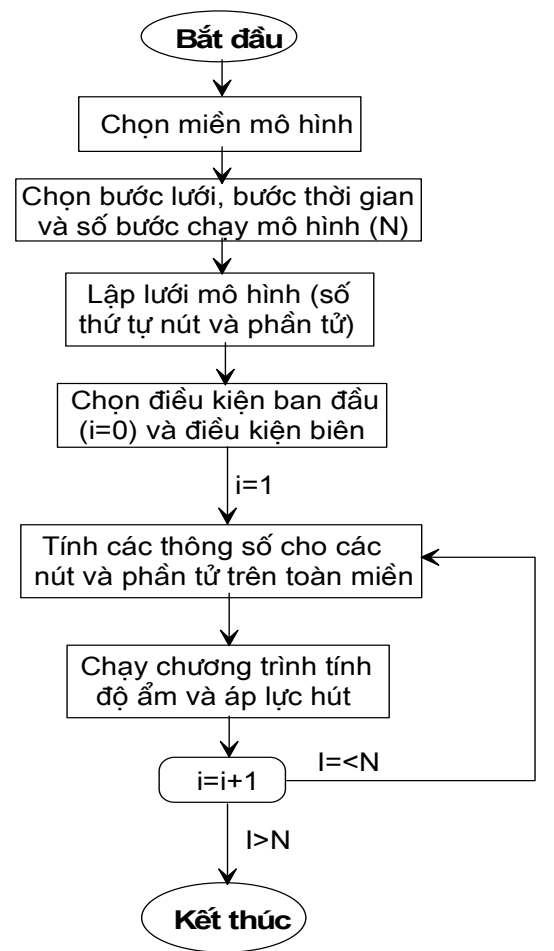

Hình 3. Sơ đồ khối quá trình mô hình số lan truyền ẩm 


\section{Mô hình thấm nước mưa khu vực nghiên cứu}

\section{1. Đặc trung mưa khu vục thị trấn Cốc Pài- huyện Xín Mần}

Số liệu mưa trung bình năm giai đoạn 20002008 tại Xín Mần cho thấy lượng mưa năm lớn nhất là 2063,8mm (năm 2008), nhỏ nhất là $693,9 \mathrm{~mm}$ (năm 2003) và trung bình là $1518,3 \mathrm{~mm}$. Trong giai đoạn này có 3 năm có tổng lượng mưa từ 2063,8mm đến $2098 \mathrm{~mm}$ là năm 2001, 2002 và 2008 và lớn gấp gần 1,4 lần mưa trung bình năm và lớn tới gấp 3 lần năm có mưa ít nhất.
Năm 2008 là năm xảy ra trượt lở mạnh ở khu vực thị trấn Cốc Pài - huyện Xín Mần - tỉnh Hà Giang, có mưa 1 ngày, 2 và 3 ngày liên tục lớn nhất xảy ra trong các ngày 26-28 tháng 8 với lượng mưa tương ứng là $156,0 \mathrm{~mm}$ (là lượng mưa ngày lớn thứ 3 trong giai đoạn 1970-2009), 202,1 mm (là lượng mưa 2 ngày lớn thứ 5 trong giai đoạn 19702009)) và 222,3mm (là lượng mưa 3 ngày lớn thứ 7 trong giai đoạn 1970-2009). Đáng lưu ý là mưa hầu như liên tục kéo dài suốt từ ngày $23 / 7$ đến hết ngày 7/9 với tổng lượng mưa đạt 791,3mm (bảng 1, hình 4) chiếm 38\% tổng lượng mưa năm 2008.

Bảng 1. Số liệu mưa từ ngày 22-7-2008 đến 7-9-2008 [5]

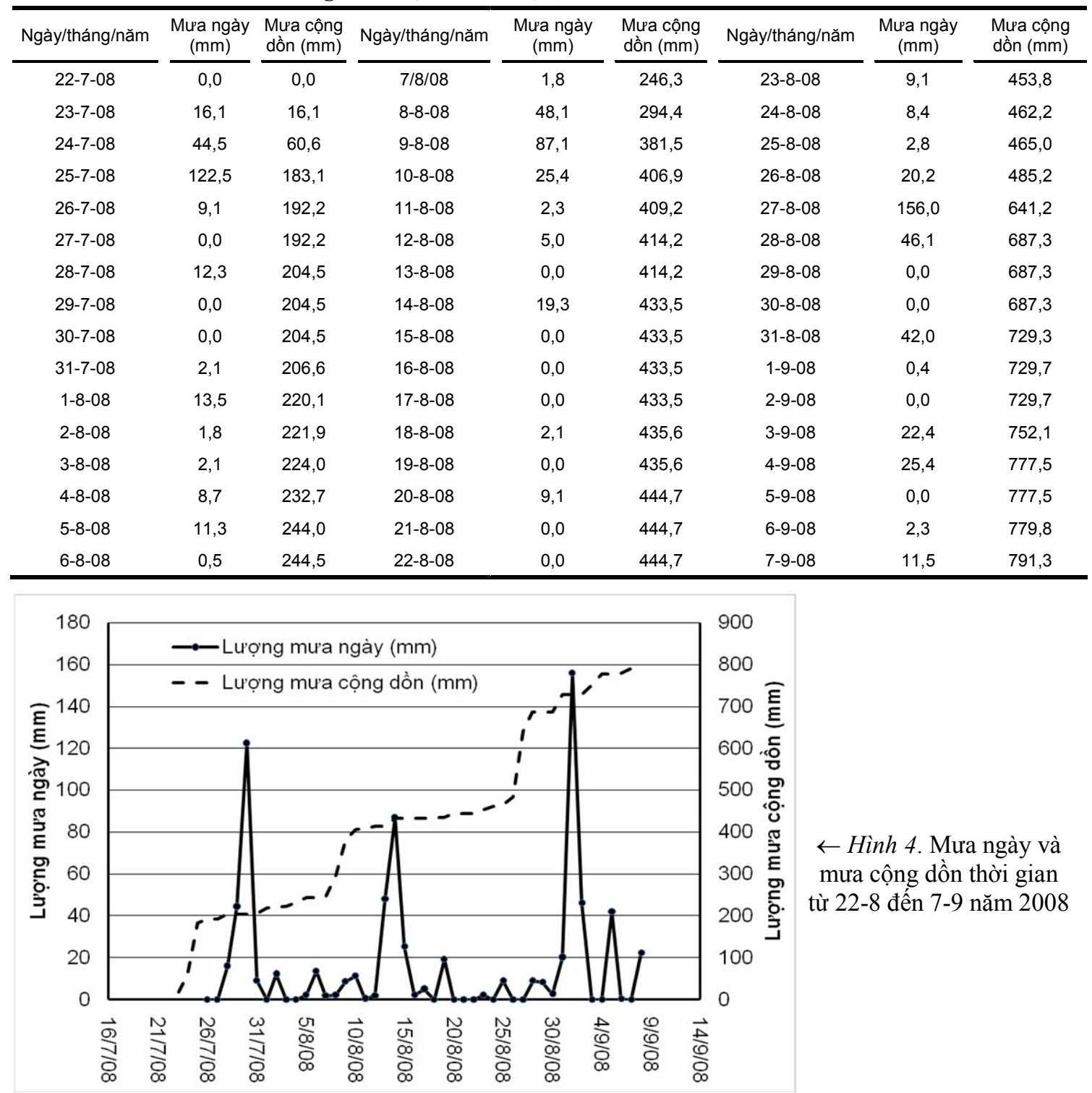




\subsection{Mô hình thấm nước mưa khu vục thị trấn Cốc Pài thời gian tù̀ 22-8 đến 7-9 năm 2008}

Tiến hành mô hình lan truyền ẩm khu vực thị trấn Cốc Pài trong thời gian mưa lớn năm 2008 từ ngày $22 / 8$ đến $7 / 9$. Số liệu mưa sử dụng trong mô hình là mưa theo giờ đo được tại Hoàng $\mathrm{Su} \mathrm{Phì}$ (hình 5) do số liệu mưa ở thị trấn Cốc Pài là số liệu mưa đo theo ngày. Mô hình phần tử hữu hạn bậc cao có miền mô hình từ mặt đất đến độ sâu $8 \mathrm{~m}$, kích thước phần tử là $0,02 \mathrm{~m}$, tức là có tổng số nút là 4000 , Bước thời gian trong mô hình là 10 phút (tổng số bước thời gian chạy mô hình là 2304). Trong khuôn khổ nghiên cứu này sử dụng tương quan giữa áp suất hút nước tuyệt đối, hệ số thấm không bão hòa và hệ số phân tán ẩm theo các công thức (2-4) nêu trên, nhưng hệ số thấm bão hoà của đất lấy bằng $0,02 \mathrm{~m} / \mathrm{ngày}$ là giá trị hệ số thấm trung bình theo tài liệu thí nghiệm thấm các mẫu đất từ mặt đất đến độ sâu 2 mét trong các lỗ khoan địa chất công trình khu vực nghiên cứu [6].

Từ kết quả phân bố ẩm của mô hình lan truyền ẩm do nước mưa ngấm có thể tính toán được lượng nước mưa ngấm vào đất và phần nước mưa chảy tràn trên mặt đất. Kết quả tính toán lượng nước mưa ngấm thể hiện trên hình 6 và 7 . Kết quả mô hình ngấm nước mưa còn cho phép tính toán phần trăm lượng nước mưa ngấm vào đất, phần còn lại là chảy tràn mặt đất, bốc hơi...

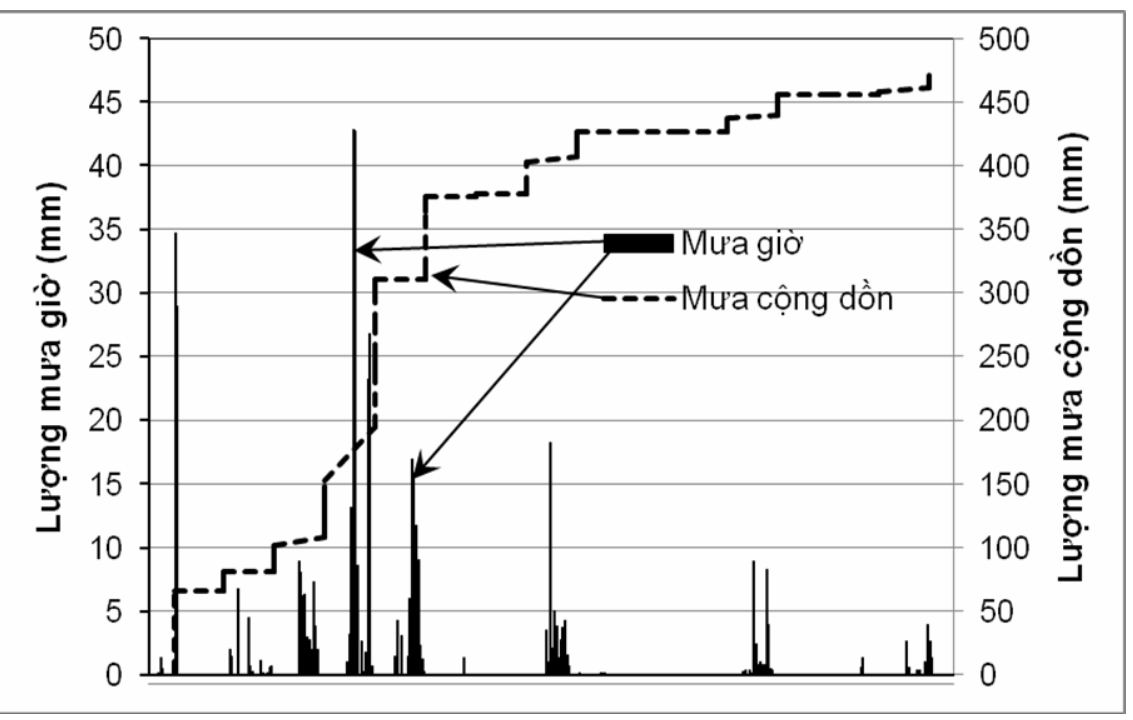

Hìn 5. Mưa giờ từ 22-8-2008 đến 7-9-2008 [5]

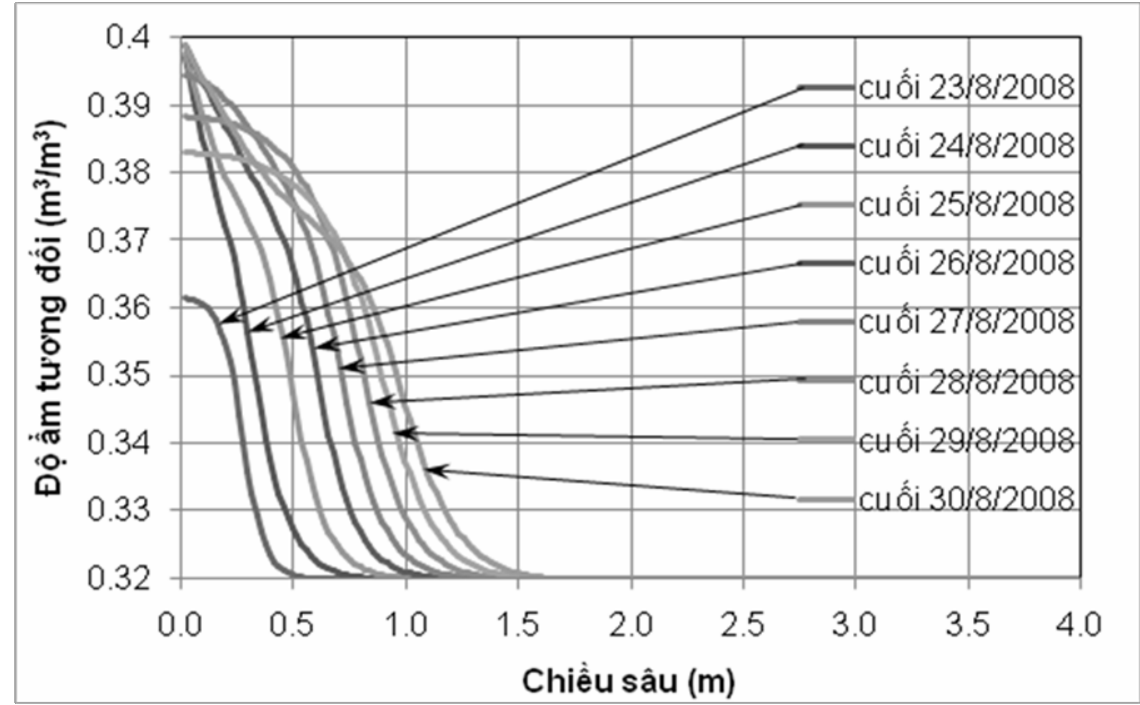

Hình 6. Phân bố ẩm theo độ sâu từ 24-8 đến 31-8 


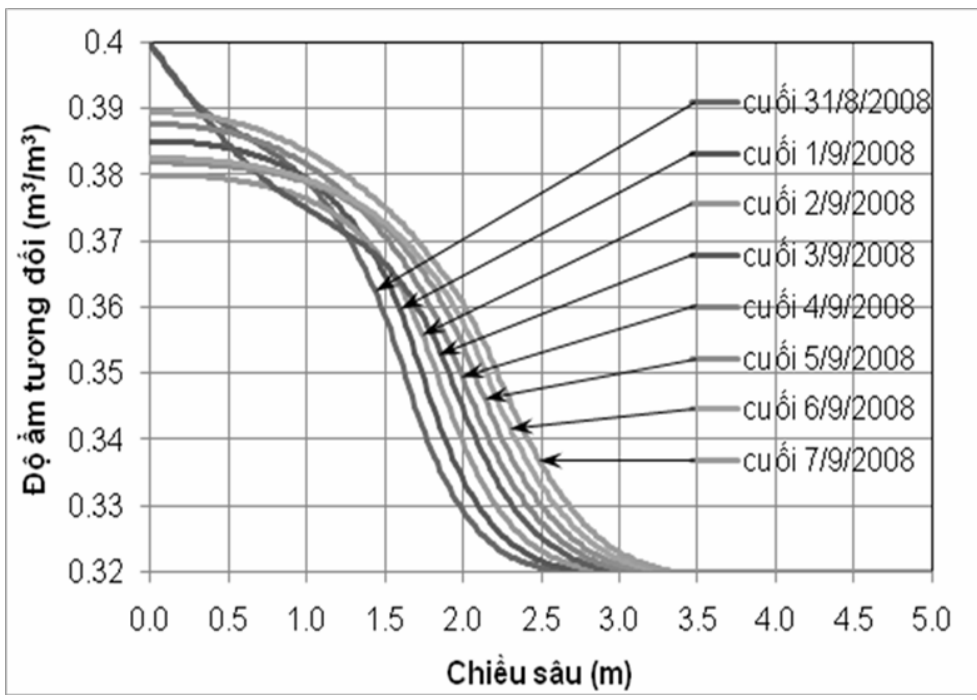

$\leftarrow$ Hinh 7. Phân bố ẩm theo độ sâu từ 31-8 đến 7-9

Kết quả cho thấy tốc độ tăng độ ẩm và chiều sâu lan truyền nước mưa trong những ngày đầu lớn và sau đó giảm dần. Điều này phản ánh đúng bản chất của quá trình vì áp suất hút nước giảm theo quy luật số mũ với độ ẩm, và giảm nhanh hơn rât nhiều so với việc tăng hệ số thấm khi độ ẩm tăng, đồng thời gradient nồng độ

ẩm theo phương thấm thẳng đứng giảm theo thời gian. Trong 5 ngày đầu mưa mới bắt đầu độ ẩm trong đất thấp, cường độ mư nhỏ nên phần trăm lượng nước mưa vào đất lớn, đạt tới $34 \%$ trong ngày thứ 3 , sau đó giảm dần đạt cực tiêu vào ngày thứ $7(14 \%)$ và sau đó tăng chậm và đạt $19 \%$ vào ngày thứ 16 (hình 8 ).

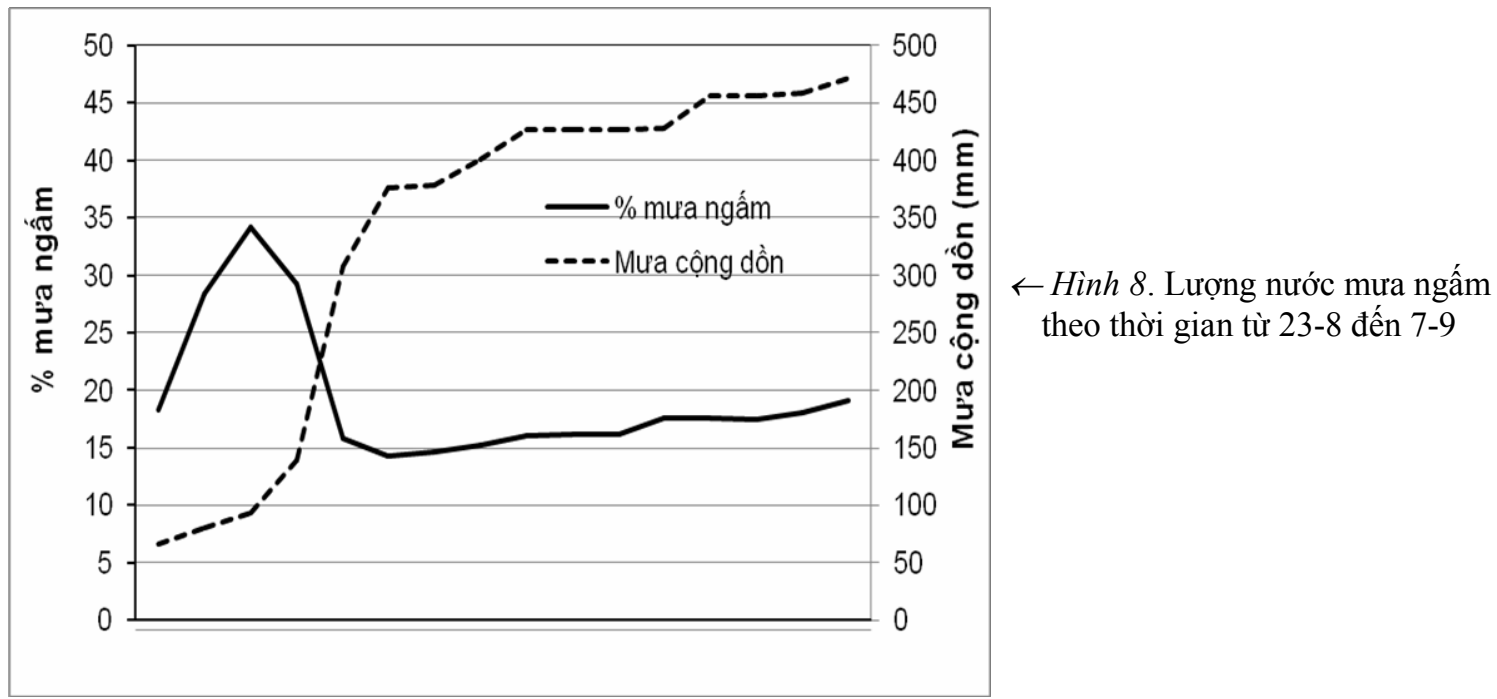

\subsection{Sử dụng kết quả mô hình ngấm nuớc mua trong tính toán độ ổn định sườn dốc}

Để sử dụng kết quả mô hình ngấm nước mưa trong tính toán độ ổn định của sườn dốc cần thiết lập mối tương quan giữa khối lượng riêng của đất và độ ẩm, tương quan giữa giá trị độ dính cũng như góc ma sát trong của đất và độ ẩm của đất. Ngoài ra nếu có điều kiện về áp lực nước lỗ rỗng (mực nước ngầm cao hơn mặt tính toán trượt) thì yếu tố này cũng phải được đưa vào tính toán. Trong quá trình tính toán độ ổn định trượt theo các phương pháp lát cắt, tính toán khối lượng đất của các lát cắt phải được thực hiện cho từng lớp mỏng theo độ sâu 
vì độ ẩm thay đổi rất lớn theo độ sâu. Đồng thời độ dính và góc ma sát tại đáy các lát cắt (cung tính toán độ ổn định trượt) cũng phải được xác định theo mối tương quan với độ ẩm.

\section{Nhận xét - kết luận}

Khu vực nghiên cứu có bề mặt là sản phẩm phong hóa có nhiều thành phần hạt thô nên có khả năng thấm nước tốt hơn sét, sét pha thông thường. Dưới điều kiện mưa kéo dài và mưa lớn ngấm vào đất tương đối nhiều làm tăng khối lượng riêng của đất đá, làm giảm các chỉ tiêu kháng cắt, dòng chảy ngầm theo hướng độ dốc của sườn dốc làm gia tăng sức đẩy trượt, có thể làm tăng mực nước ngầm cao hơn mặt trượt,... trên khu vực nghiên cứu.

Chiều sâu và lượng nước mưa thấm vào đất là hàm số của nhiều thông số (thời gian mưa, cường độ mưa, độ thấm của đất, độ ẩm ban đầu, độ ẩm bão hòa của đất, chiều sâu mực nước ngầm,...). Việc tính toán định lượng quá trình nước mưa thấm vào đất cung cấp dữ liệu quan trọng đối với việc tính toán nguy cơ trượt lở do ảnh hưởng của mưa.

Phương pháp giải tích tính ngấm nước mưa trong đất không thể thực hiện được đối với các trường hợp mưa có cường độ thay đổi theo thời gian và không gian, đặc biệt là các thông số lan truyền ẩm của đất thay đổi mạnh mẽ theo độ ẩm. Mô hình số cho phép thực hiện chính xác quá trình ngấm của nước mưa vào đất dưới các điều kiện này phục vụ cho việc tính toán đánh giá ổn định trượt của sườn dốc dưới ảnh hưởng của các chế độ mưa khác nhau.

Việc mô hình chính xác quá trình ngấm nước mưa trong đất nói chung và khu vực nghiên cứu nói riêng còn là cơ sở phục vụ xây dựng mô hình dòng chảy mặt do nước mưa chảy tràn. Đây là co sở phục vụ tính toán cân bằng nước khu vực trong đánh giá tài nguyên nước, đồng thời mô hình chính xác dòng nước mặt do nước mưa chảy tràn phục vụ các công tác thiết kế hệ thống thu gom nước mưa, đặc biệt trong công tác thiết kế các công trình chống trượt.

Ghi nhận: Bài báo được hoàn thành trong khuôn khổ thực hiện đề tài KC.08.33/06-10: Nghiên cứu đánh giá, dự báo chi tiết hiện tượng trượt-lở và xây dựng các giải pháp phòng chống cho thị trấn Cốc Pài huyện Xín Mần, tỉnh Hà Giang.

\section{TÀI LIẸU DÃNN}

[1] Robert L. Schuster và Raymond J. Krizek, 1981: Trượt đất: Nghiên cứu và gia cố, Biên tập: G, X, Zôlôtarev. Nhà xuất bản Môscơva "Mir", (Bản dịch tiếng Nga,)

[2] Peter S. Eagleson, 1978: Climate, soil, vegetation: A simplified model of soil moisture movement in the liquid phase. Water Resources Research. Volume 14, No. 5. 10/1978. Tr. 722-730.

[3] Jiunsheng Li and Hiroshi Kawano, 1997: Sprinkler Water Utilization Efficiency, Journal of International Rainwater Catchment Systems, Vol, 3, No, 1, July, 1997, pp. 41-51.

[4] Huyakorn Pinder, 1987: Computational method in subsurface flow. Academic Press.

[5] Số liệu quan trắc mưa tại thị trấn Hoàng $\mathrm{Su}$ Phì và thị trấn Xín Mần tỉnh Hà Giang lưu trữ tại Viện Khí tượng Thủy văn - Bộ Tài nguyên và Môi trường.

[6] Kết quả phân tích năm 2010 các chỉ tiêu cơ lý và thấm các mẫu đất đá lấy từ các lỗ khoan địa chất công trình thuộc đề tài KC.08.33/06-10: "Nghiên cứu đánh giá, dự báo chi tiết hiện tượng trượt-lở và xây dựng các giải pháp phòng chống cho thị trấn Cốc Pài huyện Xín Mần, tỉnh Hà Giang".

\section{SUMMARY}

\section{Rainwater infiltration modelling for slope stability analysis in Coc Pai town-Xin Man distict-Ha Giang province}

Rainfall plays an important role in formation of landslides by substantially changing the physico-mechanical properties of the soil such as soil weight, cohesion, friction angle, pore water pressure etc. For a given soil, those parameters are functions of soil moisture. Raiwater infiltration makes the change in soil moisture in space, especialliy in the depth and in time. One specific rainfall event shall give a specific rainwater infiltration and moisture distribution and therfore creates a specific distribution of physico-mechanical properties. Numerical moisture movement under given rainfall event whould give a precise moisture ditribution in soil and therefore can effectively serve the slope stability analysis and prediction. Rainwater infiltration and soil moisture movement modeling for the peak rainfall event in 2008 in Coc Pai town, Xin Man district, Ha Giang province has been carried out, which provides an important input for effective slope stability analysis and prediction of the area. 